\title{
Analysis and Research of Composite Materials Machining
}

\author{
Zhang Rong \\ Department of Mechanical Engineering, Dalian Vocational Technical College, Dalian, Liaoning, \\ 116037, China
}

Lzhch11993@sina.com

Keywords: Composite Material; Processing; Performance; Features

\begin{abstract}
This paper summarizes the classifications features and basic properties of the composite materials, The characteristics and the problems of the composite cutting are analyzed, Especially for metal-based composite materials, drawn the relationship between cutting speed and tool wear is plotted, the feed rate and tool wear diagram, cutting path and VB diagram, combine Double-layer isomerous material automobile flywheel rotor cutting example, to determine the value of various cutting parameters. The article has guiding significance for the machining of composite materials and manufacturing research.
\end{abstract}

\section{Classification and Characteristics of Composite Materials}

Definition and Characteristics of Composite Materials. Broadly speaking composite material, it is a combination of two or more components different chemical nature materials. The composite material is generally defined as: a chosen ratio of a number of two or more components (or component), through artificial composite, composition multi-phase, combined three-dimensional and with a marked interface between the phases with a special performance of the material. Composite materials have the following features.

(1)The composition and content of the composites are artificially selected and designed.

(2)Composite material is the result of man-made rather than natural formation.

(3)The component composition of the composite material after the composite retains its inherent physical and chemical properties.

(4)The properties of the composite material depend on the individual components.

(5)The composites are distinguished by a distinct interface between the components.

Classification Composite Materials. From the metal materials, inorganic non-metallic materials and organic polymers in different forms of combination, can constitute a variety of composite materials system. Composites are classified into the following categories.

By the Use of Performance Classification. It is divided into structural composite materials, functional composite materials. Composite material refers to a composite material used in the manufacture the member forced. Functional composite is a variety of special properties (e.g., damp, conductive, magnetic, shield) of the composite material.

According to the Basic Material Classification. It is divided into a polymer matrix composites, metal matrix composites, inorganic non-metallic matrix composites. Polymer matrix composites refers to an organic polymer, mainly a composite material was processed by thermosetting resin, thermoplastic resin and rubber as the base body. Metal matrix composites refer to composite materials processed into the metal as the basic body, mainly aluminum matrix composites, titanium matrix composites, magnesium matrix composites, graphite fiber reinforced metal matrix composites. Inorganic non-metallic matrix composite material is a composite material processed into a ceramic material (including glass, cement) to the basic body.

By the Form of Reinforcing Material Classification. It is divided into continuous fiber composites, short fiber composites, particulate filler, composite materials, woven composites.

By the Type of Reinforcing Fibers Classification. It is divided into the glass fiber composites, carbon fiber composite materials, organic fibers(aromatic polyamide fiber, aromatic polyester fiber, etc.) composites, metal fiber composite materials (tungsten wire, stainless steel wire, etc), ceramic fibers ( $\mathrm{AL}_{2} \mathrm{O}_{3}$ fibers, SIC fibers, $\mathrm{B}$ fibers, etc) composites. 
The Basic Properties of Composite Materials. Composite material is compared with conventional , there are two main features, namely, the material properties can be designed and materials and member forming consistency. Composite effect desired is complementary raw material (constituent material) properties, and produces a synergistic effect, the composite material has excellent physical and chemical properties.

Lightweight, High Strength. The density of glass fiber reinforced resin composite material is 1.5 $\sim 2.0 \mathrm{~g} / \mathrm{cm}^{3}$, only steel $1 / 5 \sim 1 / 4$, while the mechanical strength can exceed the level of carbon steel. Ratio strength (strength and density ratio) is calculated by significantly more than steel, even more than some of the steel.

Strong Fatigue Resistance. Metal material fatigue failure is the sudden development from the inside out, no prior warning. The fiber and matrix interface fiber composites can prevent crack propagation, therefore, always starts from fatigue damage weaknesses fiber gradually extended to combine surface, there are clear signs before failure. Fatigue limit most metallic materials is $40 \%$ to $50 \%$ of the tensile strength, while the carbon fiber composite material is a polyester of $70 \%$ to $80 \%$.

The Superior Damping Properties. Composite fibers and basic interface has damping capacity, high vibration resistance, the natural frequencies of structure has a relationship with the shape of structure itself, and also with the square root of the ratio modulus of the material(elastic modulus and density ratio),high natural frequency to avoid the early damage caused by the resonance.

Strong Chemical Resistance. Most composite materials can withstand corrosion with acid and alkali.

Superior Heat Resistance. SIC fiber metal matrix composites, $\mathrm{Al}_{2} \mathrm{O}_{3}$ fiber and ceramic composite have capability to withstand $1200 \sim 140^{\circ} \mathrm{C}$ high temperature in air, showing superior heat resistance.

\section{Composite Materials Machining}

Fiber-reinforced Polymer Matrix Composites Machining. Common characteristics of fiberreinforced polymer matrix composites(FRP) machining.

High Cutting Temperature. In the cutting process FRP cutting layer material, some were cut under the stretching action, and some were cut under shear bending. Because of the high tensile strength of the fibrous material, it need more power to cut, combined with an elastic and rough fiber material cross-section, the contact friction is serious between the tool and the fiber layer, leading to increase in cutting heat, and the thermal conductivity of fiber-reinforced polymer matrix composites is lower than the metal, formed high temperatures in the cutting zone, increased tool wear, low durability. Manufacturing tools with cemented carbide, ceramic, cermet cut fiber-reinforced polymer matrix composites, will produce hooked wear in flank.

$\boldsymbol{F R P}$ in Machining. It is high cutting temperature, it is vary greatly thermal expansion of coefficients reinforcing fiber and resin matrix, prone to residual stress, the machined surface of the dimensional accuracy and surface roughness is not easy to meet the requirements.

Due to the large plastic FRP, in cutting under high temperature and pressure, it is easy to removal the cutting of adhesion tool rake face and flank.

Metal Matrix Composites Machining. Cutting Features. There are many remnants of colporate with reinforcing fibers corresponding the machined surface to $\mathrm{AL}_{2} \mathrm{O}_{3}$ short fibers, SICW (Wwhisker) reinforced aluminum alloy 6061 for example. When a single crystal diamond cutter turning SIC whisker reinforced aluminum alloy composites SICW/6061, cutting show that the number of colporate on the machined surface related with fiber (whiskers) $v_{f}$ content rate, the more $v_{f}$, the more colporate. This is one of the basic characteristics of short fiber reinforced metal matrix composites cutting surface.

Machined surface morphology of turning MMC, three forms exist on the machined surface of the fiber, i.e. fiber fracture surface is exposed, the fiber is pulled out from the matrix, the fiber is pressed into. When the fiber size larger longer cutting edge direct contact with the fiber, the fiber was bent broken, broken section bared; single-crystal diamond tool with a sharpened cutting MMC, fine short fiber is pulled along the cutting direction; when a larger radius with a blunt cutting tool, 
the fine short fibers with the plastic flow of the matrix is pressed into the work surface.

Turning MMC Machining Characteristics. Turning workpiece material is $\mathrm{SiC}_{\mathrm{W}} / 6061, v_{f}=25 \%$; $\mathrm{SiC}_{\mathrm{W}} / 6061 \mathrm{P}, v f=25 \% ; \mathrm{Al}_{2} \mathrm{O}_{3} / 6061, v_{f}=15 \%$. Tool material is CB; C-SiC; K10A; K10B(wet cutting); $\mathrm{K} 10 \mathrm{~B}$ (dry cutting); diamond(PCD). Cutting parameters are $a_{p}=0.5 \mathrm{~mm}, f=0.1 \mathrm{~mm} / \mathrm{r}, l_{m}=50 \mathrm{~m}$. Impact of cutting velocity $\left(v_{c}\right)$ to tool wear, as shown in Fig.1(a), (b), (c). Impact of feed to tool wear, as shown in Fig.2(a), (b). Relationship cutting path $\left(l_{m}\right)$ and $V B$, as show in Fig.3(a), (b), (c).

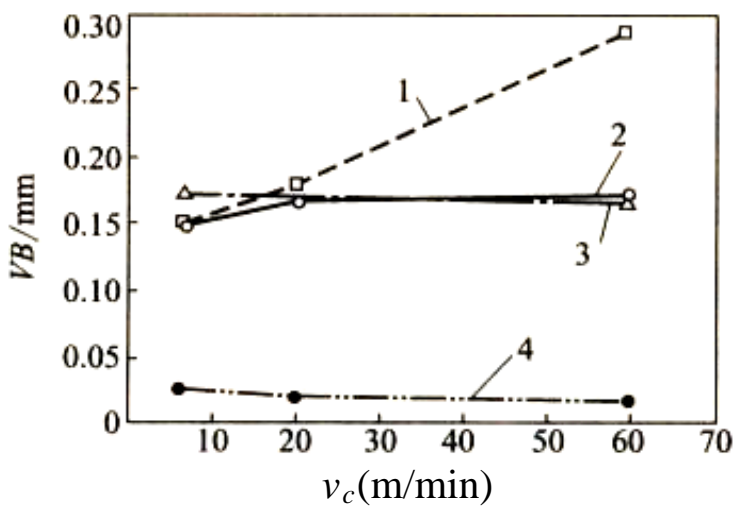

1-Ceramics, 2-K10, 3-P30, 4-diamond(PCD)

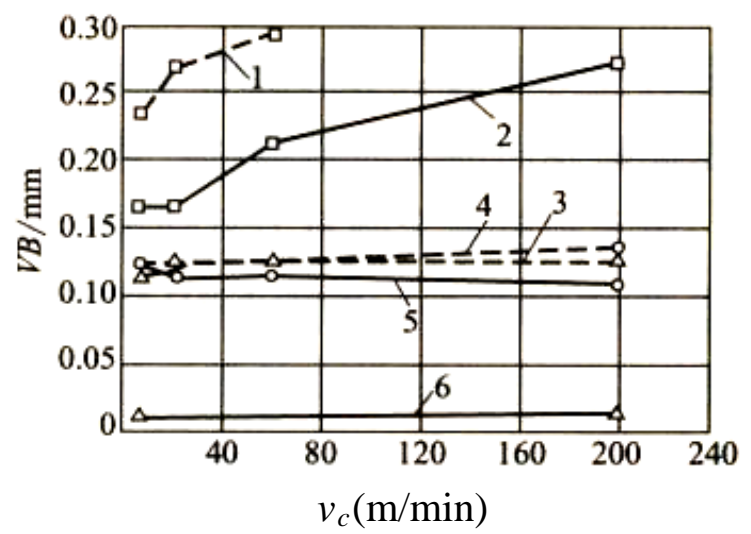

1-CB, 2-C-SiC, 3-K10A, 4-K10B(wet cutting), 5-K10B(dry cutting), 6-diamond(PCD)

(a) $\mathrm{SiC}_{\mathrm{w}} / 6061, v_{f}=25 \%$

(b) $\mathrm{SiC}_{\mathrm{w}} / 6061, v_{f}=25 \%$

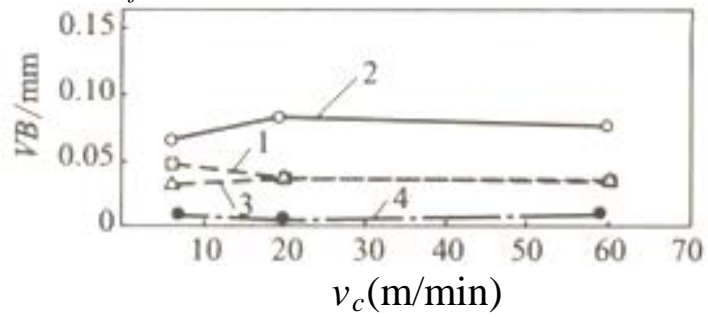

1-Ceramics, 2-K10, 3-P30, 4-diamond(PCD)

(c) $\mathrm{Al}_{2} \mathrm{O}_{3} / 6061, v_{f}=15 \%$

Fig. 1 relationship between cutting velocity $\left(v_{c}\right)$ and tool wear $\left(a_{p}=0.5 \mathrm{~mm}, f=0.1 \mathrm{~mm} / \mathrm{r}, l_{m}=50 \mathrm{~m}\right)$
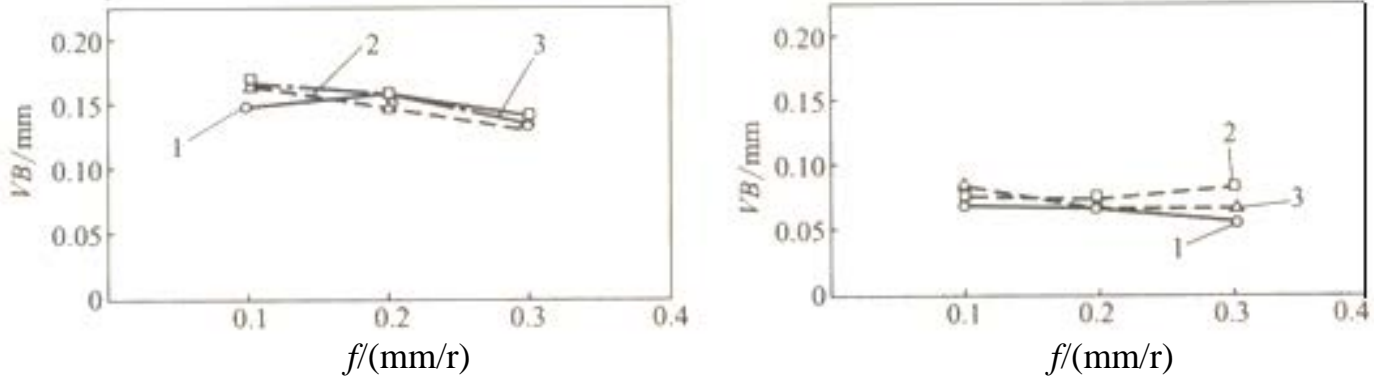

$1-v_{c}=6 \mathrm{~m} / \mathrm{min}, 2-v_{c}=20 \mathrm{~m} / \mathrm{min}, 3-v_{c}=60 \mathrm{~m} / \mathrm{min}$

(a) $\mathrm{SiC}_{\mathrm{w}} / 6061, v_{f}=25 \%$

(b) $\mathrm{Al}_{2} \mathrm{O}_{3} / 6061, v_{f}=15 \%$

Fig.2 relationship feed and $V B$

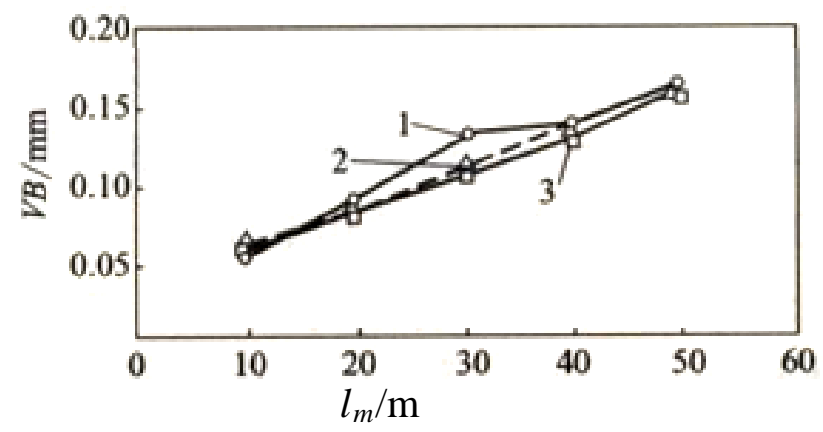

(a) $\mathrm{SiC}_{\mathrm{w}} / 6061, v_{f}=25 \%, \mathrm{P} 30, f=0.1 \mathrm{~mm} / \mathrm{r}$

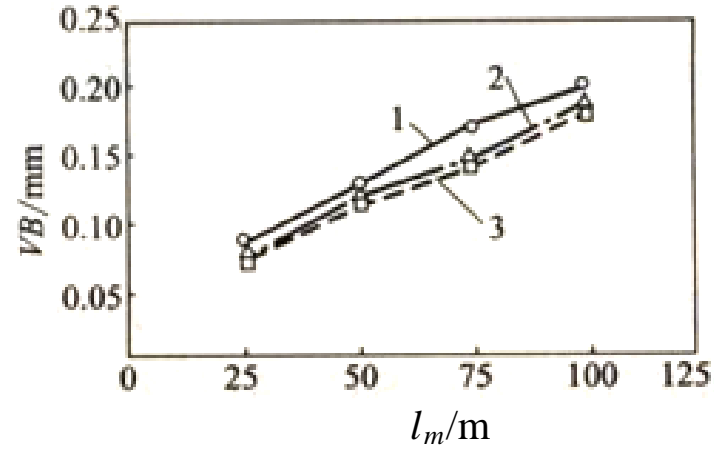

(b) $\mathrm{SiC}_{\mathrm{w}} / 6061 \mathrm{P}, v_{f}=25 \%, \mathrm{~K} 10, f=0.2 \mathrm{~mm} / \mathrm{r}$ 


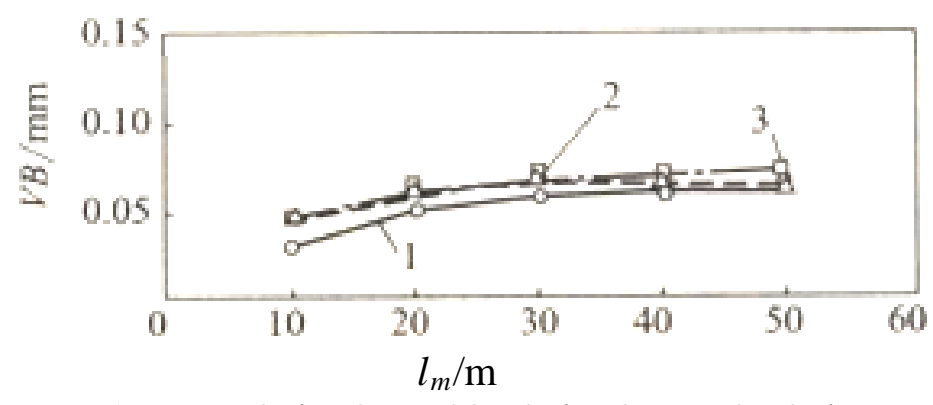

$1-v_{c}=6 \mathrm{~m} / \mathrm{min}, 2-v_{c}=20 \mathrm{~m} / \mathrm{min}, 3-v_{c}=60 \mathrm{~m} / \mathrm{min}$

(c) $\mathrm{Al}_{2} \mathrm{O}_{3} / 6061, v_{f}=15 \%, \mathrm{~K} 10, f=0.1 \mathrm{~mm} / \mathrm{r}, a_{p}=0.5 \mathrm{~mm}$

Fig.3 relationship cutting path $\left(l_{\mathrm{m}}\right)$ and $V B$

\section{Example for Composite Materials Machining}

Automotive flywheel rotor is made of double-layer isomerous composite material, as shown in Fig.4, the rotor inner diameter is $\Phi 50 \mathrm{~mm}, t_{1}$ ring is 149 aramid/epoxy composite, $t_{1}=18.0 \mathrm{~mm}, t_{2}$ ring is T300/5208 carbon/epoxy composite, $t_{2}=38.8 \mathrm{~mm}$, rotor height $h=100 \mathrm{~mm}$. 149 aramid reinforcing fiber/epoxy composite material has a density of $1380 \mathrm{~kg} / \mathrm{m}^{3}$, ring tensile strength was $1280 \mathrm{MPa}$, radial tensile strength was $30 \mathrm{MPa}$, the elastic modulus is $87 \mathrm{GPa}$ along the fiber direction. The density T300/5208 composite material is $1600 \mathrm{~kg} / \mathrm{m}^{3}$, ring tensile strength is $1080 \mathrm{MPa}$, radial tensile strength is $39 \mathrm{MPa}$, the elastic modulus is $181 \mathrm{GPa}$ along the fiber direction, the rotor speed is $60000 \mathrm{r} / \mathrm{min}$, the angular velocity is $\omega=6283.2 \mathrm{rad} / \mathrm{s}$.

Flywheel rotor processing is mainly turning inside and outside the circle and the two ends. Using a CVD diamond film tool. Rake angle $\gamma_{0}=0^{\circ}$, after angle $\alpha_{0}=7^{\circ}$. Cutting parameters: $v_{c}=11.3 \mathrm{~m} / \mathrm{min}$, $f=0.02 \mathrm{~mm} / \mathrm{r}, a_{p}=0.05 \mathrm{~mm}$, it is not serious before flank wear.

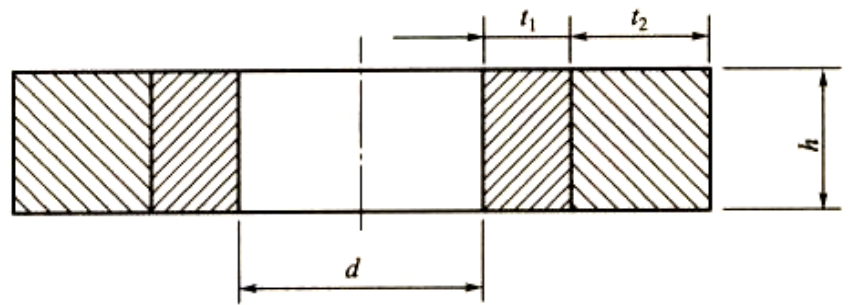

Fig.4 flywheel rotor

\section{References}

[1] Yan binghua. SiC Particle Reinforced Alloy Composites Machining, Light Metal ,Vol.43.No.4.

[2] N.Tom ac, etc. Machinability of Particulate Aluminium Matrix Composited Annals of the CIRP 1992;41(1)

[3] Huang Jiakang. Composites Forming Technology. Beijing Chemical Industry Press,2008

[4] Geng Lin. Precision Cutting Research SiC Whisker Reinforced Aluminum Matrix Composites, Metal Science and TechnologyWelder.1992;12

[5] Ping Chen, etc. Paper for Presentation at the ASM INTERNATIONAL,1989; 9 